\title{
ARTIGO
}

\section{UM ESTUDO SOBRE AS CAUSAS QUE GERAM A INDISPONIBILIDADE NO PROCESSO DE FABRICAÇÃO DE PEÇAS AUTOMOTIVAS ${ }^{1}$}

\author{
Andressa Amaral de Azevedo \\ Tiago Silveira Gontijo \\ Érick Furtado Victor \\ Leonardo Lopes de Souza \\ Taís Jane de Oliveira
}

\section{RESUMO}

Este trabalho teve como objetivo mapear as principais causas que afetam a disponibilidade de uma máquina injetora, que é parte do processo de fabricação de componentes automotivos. Para tanto, foi feito um estudo comparativo entre a disponibilidade estabelecida e realizada entre os meses de setembro de 2016 a abril de 2017. Constatou-se que o índice médio de atendimento, de $94,98 \%$, foi inferior à meta de $97 \%$ traçada. Posteriormente, identificaram-se os principais fatores responsáveis por tal situação, onde se pôde constatar, por meio da aplicação de um Gráfico de Pareto que, $75 \%$ das paradas ocorridas estavam associadas à troca do componente denominado como "Macho Vareta". Após identificação da(s) falha(s) mais significativa(s), foi realizado um brainstorming junto aos colaboradores do setor de engenharia envolvidos no processo produtivo. Em seguida, realizou-se, através de um diagrama de Ishikawa um processo de estratificação deste fator identificado como principal, obtendo-se assim as principais causas que originavam as paradas do equipamento. A metodologia aplicada constituiu-se nos seguintes procedimentos: análise do número de horas em que as máquinas ficam paradas, fornecidos pela Empresa Alfa, realização de quatro visitas in loco com o desenvolvimento de entrevistas não estruturadas junto aos envolvidos no processo e aplicação de ferramentas da qualidade para identificação das situações envolvidas. Por meio destas análises pode-se realizar o mapeamento das principais causas que afetam a disponibilidade do equipamento estudado, sendo estas: falha no posicionamento do sensor de atuação dos machos; falha elétrica no sinal de comando dos sensores; falha de segurança hidráulica; sequência de fechamento inadequada dos machos; falta de monitoração das variáveis do processo. Como resultado, a estimativa de disponibilidade foi $98,66 \%$.

Palavras-chave: Mapeamento de falhas. Disponibilidade. Manutenção.

\section{INTRODUÇÃO}

O Brasil é um país que vem passando por diversas mudanças, tanto no cenário político, como no econômico. Sob este contexto, nota-se significativa desaceleração do mercado nacional (BAENINGER, 1996). Esta situação tem feito com que empresas busquem diferenciais que possam ser indispensáveis no que tange a mantê-la ou retirá-la do mercado. Desta forma, o aumento da eficiência dos processos produtivos passa a ser um ponto chave para a sobrevivência da empresa (CASSIOLATO; SZAPIRO, 2015).

Considerando o setor automobilístico, em que as empresas encontram-se inseridas em um ambiente altamente competitivo, o aproveitamento dos recursos produtivos de maneira eficiente configura-se como uma necessidade. Diante do exposto, é digno de nota que o número de

\footnotetext{
${ }^{1}$ Como citar este artigo: AZEVEDO, Andressa Amaral de et al. Um estudo sobre as causas que geram a indisponibilidade no processo de fabricação de peças automotivas. ForScience: revista científica do IFMG, Formiga, v. 6, n. 3, e00272, jul./dez. 2018.
}

${ }^{2}$ Autor para correspondência: Andressa Amaral de Azevedo, PUC Minas, e-mail: andressa@pucminas.br 
licenciamentos de veículos novos no Brasil, de janeiro a maio de cada ano, apesar da forte queda sofrida nos últimos anos, apresentou um pequeno crescimento de 1,6\% no ano de 2017 (ANFAVEA, 2017).

O setor de autopeças precisa atender às necessidades de fabricação da indústria automotora, com produção eficiente aliada a qualidade dos produtos. O processo de fabricação de componentes automotivos, sob a ótica de utilização de meios de fundição, requer significativa disponibilidade dos equipamentos envolvidos. A frequente ocorrência de paradas compromete, entre outros, os desafios em relação aos custos, fator crucial na disputa entre as empresas (MUNARIN et al., 2013). A disponibilidade de um equipamento é afetada basicamente por dois motivos: paradas programadas (manutenções, setup, etc.) ou não programadas (falha nos equipamentos, mão de obra, falta de matéria prima, entre outros) (MENDES; RIBEIRO, 2014).

Diante deste contexto, o objetivo geral do artigo é mapear as principais causas que geram a indisponibilidade no processo de fabricação de peças automotivas. Especificamente, pretendese calcular a disponibilidade do equipamento alvo deste estudo e identificar os fatores que ocasionam o processo de parada, apontando suas principais causas. Para tal, pretende-se fazer uso de algumas ferramentas de Gestão da Qualidade, a saber: brainstorming, diagrama de Pareto e diagrama de Ishikawa. A empresa, objeto deste estudo, aqui denominada Alfa, é uma multinacional localizada na região metropolitana de Belo Horizonte, especializada na produção de componentes automotivos em alumínio, em especial blocos de motores, cabeçotes e peças de transmissão.

Além dessa introdução, este artigo contém mais quatro sessões. A segunda discute o tema do trabalho, por meio de uma revisão bibliográfica. Na terceira é apresentada a metodologia aplicada. Na seção quatro expõem-se os resultados obtidos. Por fim, têm-se as considerações finais.

\section{REFERENCIAL TEÓRICO}

Considerando as diversas transformações no cenário econômico nos últimos anos, a produtividade tem se tornado um dos conceitos de fundamental importância para as organizações (GORGULHO, 2014). Esta, aliada à qualidade, forma o binômio responsável pelo que há de mais eficaz para aumentar o desempenho e dar competitividade às empresas. Xenos (2004) por sua vez, afirma que uma organização altamente competitiva é aquela que possui a maior produtividade entre todos os seus concorrentes o que, por sua vez, torna-se a melhor forma de se garantir a sobrevivência no mercado. Produtividade é a capacidade de "produzir cada vez mais e/ou melhor com cada vez menos" (CAMPOS, 2004, p. 3). Tal conceito pode ser mensurado por meio da relação entre o custo de produção e o faturamento gerado, o que também pode ser entendido como a capacidade que as companhias possuem de agregar valor.

Campos (2004, p. 2) esclarece que um "produto ou serviço de qualidade é aquele que atende perfeitamente, de forma confiável, de forma acessível, de forma segura e no tempo certo as necessidades do cliente". Embora existam várias formas de conceituação da qualidade, Pinto e Xavier (2001, p. 23) afirmam que "a falta de qualidade [...] provoca o retrabalho, que nada mais é 
do que uma falha prematura". Pela perspectiva do mercado, em especial o automobilístico, a qualidade, em todos os âmbitos, passa a ser um fator estratégico, no qual seu investimento é forma de atuação para se competir.

Várias são as ferramentas que podem ser utilizadas para a análise de dados onde, no processo de gestão da qualidade, destaca-se a metodologia de análise por meio do gráfico de pareto. Conforme definido por Werkema (1995, p. 71), “o gráfico de pareto é um gráfico de barras verticais que dispõe a informação de forma a tornar evidente e visual a priorização de temas". Campos (2004) elenca três aspectos principais que o método de análise de pareto permite: (i) Estratificar um problema macro, dividindo-o em problemas menores e mais fáceis de serem resolvidos; (ii) Priorizar projetos; (iii) Estabelecimento de metas concretas e atingíveis. Geralmente existem poucos problemas de maior impacto e muitos que são triviais.

\subsection{Manutenção Industrial}

Oriundo do latim manustenere, manutenção significa manter o que se tem. A NBR 5462 a define como sendo "a combinação de ações [...] destinadas a manter ou recolocar um item em um estado no qual possa desempenhar uma função requerida” (ABNT, 1994, p. 7). Xenos (2004, p. 18) resume manutenção como "fazer tudo que for preciso para assegurar que um equipamento continue a desempenhar as funções para as quais foi projetado, num nível de desempenho exigido". Atualmente, há um cenário no qual as empresas necessitam trabalhar a cultura da manutenção como um fator importante na melhoria da disponibilidade dos equipamentos, que não seja limitada a atuar somente diante da falha já ocorrida, mas principalmente em ações de melhoria do processo, visando elevar a produtividade e baixar o custo. Com objetivos distintos, as ações de manutenção de equipamentos são divididas em dois tipos: atividades de manutenção e atividades de melhoria.

As atividades de manutenção visam manter, nos equipamentos, "suas condições originais de operação e seu desempenho através do restabelecimento de eventuais deteriorações destas condições", não necessariamente ocasionando aumento de produtividade ou confiabilidade (XENOS, 2004, p. 20). Por sua vez, atividades de melhoria visam, segundo Xenos (2004, p. 20), "melhorar suas condições originais de operação, desempenho e confiabilidade intrínseca", objetivando novos patamares de produtividade. Além de ser responsável por manter e recompor condições físicas do maquinário, a manutenção também tem a função de conservar e garantir a capacidade funcional da máquina, ou seja, assegurar a condição de desempenho das atividades pelo equipamento. O supracitado autor também afirma que as duas condições - física e funcional - estão interligadas, pois "a manutenção da condição física do equipamento tem como objetivo final a manutenção da sua capacidade funcional, além da qualidade do produto". Historicamente, a manutenção é classificada em preventiva e corretiva embora, recentemente, tenham surgido demais conceitos, como os de preditiva e produtiva total (MISRA, 2008; MARTINS; LAUGENI, 2012).

Mencionada por Xenos (2004) como sendo o coração das atividades de manutenção, a preventiva consiste, basicamente, na substituição de componentes em períodos previamente 
estabelecidos. Marcorin e Lima (2003) esclarecem que este método baseia-se em intervenções periódicas programadas conforme especificações dos fabricantes dos equipamentos.

Uma vez implantada, a manutenção preventiva “deve ter caráter obrigatório" (XENOS, 2004, p. 24). O autor aborda, também, que embora a manutenção preventiva tenha um custo mais dispendioso pelo fato de promover a troca de peças, antes que estas atinjam seus limites de vida útil, quando executada de forma correta e planejada, proporciona a redução da ocorrência de falhas, a diminuição das interrupções inesperadas e o aumento da Disponibilidade. Neste contexto, destaca-se que, segundo Marcorin e Lima (2003, p. 39), a manutenção corretiva é assertiva "quando os custos da indisponibilidade são menores do que os custos necessários para evitar a falha”. Para Smith (2017) a adoção da manutenção preditiva parte do pressuposto de que existe uma solução ótica, que está centrada em intervir na máquina ou equipamento em um momento específico.

Em relação ao método preventivo, a manutenção preditiva visa melhorar a troca de componentes, e estender o intervalo entre uma manutenção e outra; isto se dá por meio da utilização de análises estatísticas que preveem quando a peça estará próximo do seu limite de vida (XENOS, 2004). Dhillon (2006), por sua vez incrementa esta explanação ao considerar a manutenção preditiva como uma maneira de "enfocar" a manutenção preventiva, ou seja, ela busca antecipar à ocorrência de falhas. Conforme defendido por Pinto e Xavier (2001), Disponibilidade é o principal objetivo das ações de manutenção. Os autores conceituam-na como sendo a relação entre o tempo em que um equipamento esteve disponível para operar em relação ao tempo total disponível. Lafraia (2001) complementa a definição anterior indicando que disponibilidade é a probabilidade de que uma máquina esteja em condição operacional em um determinado instante. Algumas variáveis são importantes para o entendimento e cálculo da Disponibilidade: (i) Tempo total: tempo em que o equipamento poderia estar disponível; (ii) Tempo de funcionamento: tempo em que, de fato, a máquina esteve operando e (iii) Tempo de não funcionamento: tempo em que o equipamento ficou parado, ou seja, indisponível para a produção.

Desta forma, é possível calcular a Disponibilidade por meio da Equações (1) e (2):

$$
\begin{gathered}
I D F=\frac{\mathrm{TT}-\mathrm{TP}}{\mathrm{TT}} \\
I D F=\frac{\mathrm{TMEF}}{\mathrm{TMEF}+\mathrm{TMPR}}
\end{gathered}
$$

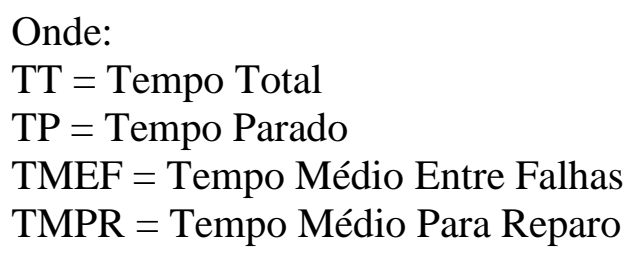

Pinto e Xavier (2001, p. 102) esclarecem que, ao longo do tempo total, tem-se "tempos disponíveis para a produção e tempos em que o equipamento está em manutenção". De acordo com os autores Pinto e Xavier (2001), para que se possa melhorar o Índice de Disponibilidade 
dos equipamentos é preciso: (i) Aumentar a confiabilidade do tempo médio entre falhas; (ii) Reduzir o tempo médio para reparo e (iii) Aumentar TMEF e reduzir o TMPR simultaneamente. Especificamente no que tange à falha, a NBR 5462 (ABNT, 1994, p. 3) define que "é o término da capacidade de um item desempenhar a função requerida”. Pinto e Xavier (2001, p. 99) ampliam tal conceito caracterizando-a como a "cessação da função de um item ou incapacidade de satisfazer a um padrão de desempenho previsto".

Um modelo de falha característico é representado por meio da curva da banheira. Conhecida devido ao seu formato, a mesma apresenta satisfatoriamente a combinação de diferentes modelos de falhas, representando graficamente o comportamento da frequência de ocorrências destas (XENOS, 2004). Ao discorrer sobre o tema, Xenos (2004) aborda que, dependendo das funções exigidas do equipamento, determinadas condições podem ou não serem vistas como falhas. Sendo assim, as falhas devem estar sempre associadas a parâmetros mensuráveis de modo que os critérios estabelecidos não se tornem ambíguos.

\section{MATERIAIS E MÉTODOS}

A presente pesquisa é produto do monitoramento do processo de fabricação da Empresa Alfa. Foram disponibilizados pela mesma, dados relativos ao processo em análise, referente aos meses de setembro de 2016 a abril de 2017. Além da pesquisa documental, foram realizadas quatro visitas técnicas na Empresa Alfa. Nestas visitas de campo foram feitas entrevistas não estruturadas com os funcionários e o supervisor responsável pelo processo em estudo. De posse dos dados relativos ao processo de fabricação de peças injetadas em alumínio sob pressão, foi realizado um diagnóstico acerca da Disponibilidade da máquina injetora BUHLER 1800-01, responsável pela fabricação do componente carcaça da caixa de câmbio.

Inicialmente, foi realizado um comparativo entre a Disponibilidade almejada pela empresa, e o realizado atualmente. Com isso, pretendia-se conhecer as reais condições do processo, além de utilizar tais informações como referência para identificação das principais causas que afetavam a disponibilidade do mesmo. A partir da obtenção dos dados disponibilizados pela Empresa Alfa, as falhas mais significativas foram identificadas por meio da utilização do Gráfico de Pareto. Após identificação da(s) falha(s) mais significativa(s), foi realizado um brainstorming junto aos colaboradores do setor de engenharia de processos envolvidos no processo produtivo. O mesmo teve como intuito realizar o levantamento dos principais fatores, ou seja, as variáveis críticas que ocasionam a situação identificada como causa(s) principal (ais) das paradas. Este método foi desenvolvido com uma amostra de cinco colaboradores em um universo de seis, valor referente ao total de funcionários que compõem o setor.

Visto isso, foi elaborado um fluxo de processo, contendo os fatores significativos identificados, e para as situações aplicáveis, seus pontos críticos. Com intuito de dar sequência ao trabalho, realizou-se um novo processo de brainstorming que, desta vez, além dos cinco integrantes do setor de engenharia de processos, também contou com a participação do gestor da equipe de manutenção. A presença do mesmo foi de significativa importância pelo fato de que, o objetivo deste novo processo, foi realizar a estratificação das principais falhas associadas às 
variáveis críticas identificadas. Posteriormente, utilizou-se como ferramenta de análise o Diagrama de Causa e Efeito, que proporcionou apontar as causas raízes que afetavam a Disponibilidade do equipamento alvo de estudo. Desta maneira, foi possível mapear a situação analisada e atender ao objetivo proposto.

\section{APRESENTAÇÃO E ANÁLISE DOS RESULTADOS}

\subsection{Processo Produtivo}

A Máquina Injetora Buhler 1800-01, equipamento cujas causas de paradas foram objetivo de mapeamento neste estudo, é utilizada no processo de fabricação de peças injetadas em alumínio sob pressão. Um modelo desta máquina pode ser visualizado na FIG. 1 (a). Projetada para trabalhar com uma força de fechamento de até $1800 \mathrm{Kg}$, a mesma atua com um sistema de pistão e cilindros que injetam o metal líquido aquecido em uma matriz, e após seu resfriamento realizam a remoção por meio de um sistema de extração. A referida máquina é composta pelas seguintes partes: placa impulsora; placa móvel; placa fixa; tirantes; sistema de alavancas; braço de fecho; base da máquina; sistema de injeção; meios moldes.

O produto resultante do processo de fabricação, cujas causas de paradas do equipamento Buhler 1800-01, foram objeto de estudo deste trabalho, é a carcaça F-15 da caixa de câmbio. Um modelo deste produto pode ser visualizado na FIG. 1 (b):
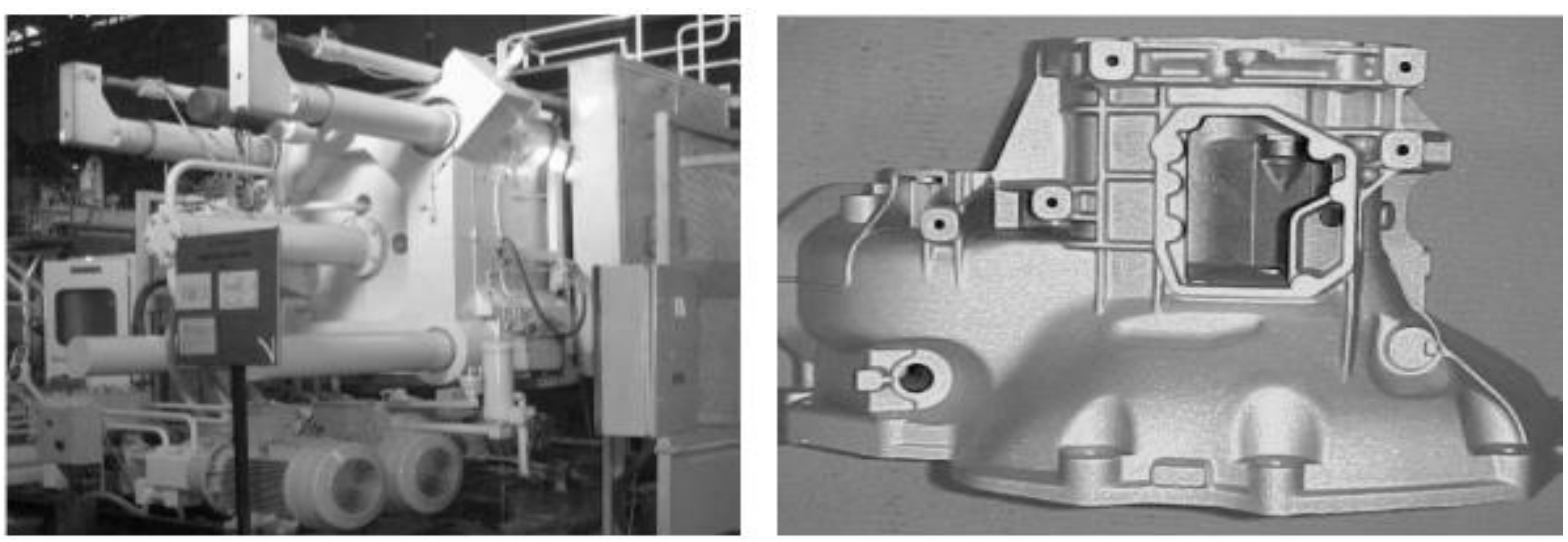

Figura 1 - Máquina Injetora (a) e Carcaça F-15 da caixa de câmbio (b) Fonte: Dos autores (2017).

Os materiais produzidos pelo processo metalúrgico, nos dias atuais, necessitam de novos recursos aplicados à produção, que estão diretamente ligados à qualidade. Os componentes automotivos encontram-se inseridos em uma classe, cuja necessidade de desempenhar adequadamente o seu propósito, é bastante significativa. Em decorrência desta situação, algumas características importantes devem ser consideradas, tanto no processo de fabricação, quanto nos próprios produtos, sendo elas: ausência de trincas superficiais; ausência de trincas na rebarba; ausência de trincas internas; preenchimento completo pelo metal na cavidade da matriz quando da confecção do produto; utilização de temperatura adequada para forjamento do metal, bem como para trabalho da matriz. 
Desenvolvida com o propósito de suportar a caixa de câmbio, quando da montagem do veículo, a carcaça F-15 atua como uma espécie de revestimento protetor. Seus frisos laterais cruzados na parte externa da carcaça servem para aumentar a rigidez e reduzir o ruído interno. Especificamente no tocante ao processo produtivo, a carcaça F-15 da caixa de câmbio é produzida por meio do processo de fundição sob pressão com ligas de alumínio líquido. Este processo, tipicamente utilizado pela engenharia automobilística, destaca-se pelo fato de produzir componentes de construção leves, característica importante para a montagem dos veículos, no que tange a obtenção de um melhor desempenho do automóvel.

Aliada a esta característica, este tipo de processo de fundição, é tido como o mais produtivo e econômico. Entre as principais vantagens deste método de produção, destaca-se o fato do alumínio ser um elemento relativamente fácil de fundir, além de se tratar de um metal reciclável (BUHLER GROUP, 2013). O processo inicia-se com a preparação dos fornos sob pressão, por meio da realização do processo de liga. Posteriormente realiza-se a etapa de lubrificação e aplicação do desmoldante. Realiza-se então o procedimento de fechamento e blocagem para assim proceder com a injeção e solidificação. Para realização desta etapa utiliza-se um sistema de pistão e cilindros, pelo qual o metal líquido aquecido é devidamente injetado em uma matriz. Após a solidificação do material realiza-se a abertura e extração da peça. Depois de extraído realiza-se a quebra das bolsas e em seguida o resfriamento da peça com utilização de água. Passa-se a partir daí, para o processo de rebarbação preliminar. Após o mesmo, as peças são devidamente embaladas e encaminhadas a um fornecedor externo que realiza o procedimento de granalha e rebarbação final. Posteriormente as peças são devolvidas e após passarem por um processo de usinagem para furação, são encaminhadas para armazenamento e posterior expedição.

\subsection{Processo de Manutenção}

Grande parte das empresas vem passando por significativas mudanças quando o enfoque é a gestão da manutenção. As organizações têm demonstrado, cada vez mais, preocupação em manter seus recursos disponíveis, do que simplesmente em realizar a recuperação dos mesmos. Alerta a esta situação, a Empresa Alfa conta com dois grandes setores de manutenção: o setor de Tecnologia de Manutenção e o setor de Engenharia de Manutenção. A Tecnologia de Manutenção é o departamento responsável pela execução das atividades de manutenção dos sistemas e equipamentos ligados a centros de custo produtivos. O departamento de Tecnologia de Manutenção se subdivide nas seguintes categorias: Tecnologia de Manutenção do Vazamento em Coquilha; Tecnologia de Manutenção da Macharia; Tecnologia de Manutenção do Vazamento Sob Pressão; Tecnologia de Manutenção do Acabamento e Usinagem; Tecnologia de Manutenção de Fornos. Já a Engenharia de Manutenção é o departamento responsável pela execução das atividades de manutenção dos sistemas e equipamentos ligados a centros de custo de suporte (não produtivos) e por prover suporte técnico de engenharia para os departamentos de Tecnologia de Manutenção. 
A Empresa Alfa adota em suas operações basicamente três tipos de manutenções: manutenção corretiva - realizada após a ocorrência de uma pane, que necessariamente acarreta parada de produção, tendo por finalidade restaurar a aptidão dos equipamentos, em caráter de emergência; manutenção preventiva - serviços originados dos planos de manutenção, efetuados em intervalos pré-determinados destinada a reduzir a probabilidade de falha ou degradação do funcionamento de um item; manutenção preditiva - todos os serviços que tem a finalidade de prever a ocorrência de falhas em um item através de inspeções e/ou equipamentos de análise. Sempre que se verifica qualquer tipo de problema, no equipamento alvo de estudo deste trabalho, acarretando temporariamente na indisponibilidade do mesmo, aciona-se o setor de Tecnologia de Manutenção, para que o mesmo realize as intervenções corretivas necessárias.

Este processo tem início com a constatação da quebra da máquina. Após tal situação o responsável pela produção abre o Reporte de Falha (RF) e na sequência abre a nota no SAP. Posteriormente o mesmo realiza a entrega do RF para a manutenção. Após o recebimento do mesmo, o responsável pelo setor, cria a ordem de manutenção. Em seguida, realiza-se o registro do RF na planilha de execução e coloca-se a mesma no escaninho de aberto. A partir daí o RF é devidamente repassado para o executor que realiza a atividade necessária. Após a execução da atividade, o responsável pela mesma assina o RF, podendo ser então constatadas as seguintes situações: se o RF preenchido apresentar carga horária superior a 2 horas, o responsável pelo setor de manutenção também realiza a assinatura do RF, separa a folha verde que é devidamente entregue a operação, que a coloca no escaninho de executado.

Após tal situação o responsável pelo setor de engenharia de manutenção recolhe a folha branca do RF, realiza o lançamento do mesmo na planilha de controle e posteriormente realiza o arquivamento deste. Caso o RF preenchido não apresente carga horária superior a 2 horas não há necessidade de se entregar a via verde à operação, devendo-se passar diretamente às atividades desenvolvidas pela engenharia de manutenção, que consistem no recolhimento da folha branca do RF, realização do lançamento do mesmo na planilha de controle e arquivamento deste. Tido como o grande objetivo da gestão da manutenção, a disponibilidade dos recursos produtivos é o foco de todos os envolvidos neste processo. Para monitorar a disponibilidade destes, normalmente as empresas estabelecem parâmetros, em forma de indicadores. No caso da Empresa Alfa, verificou-se que a disponibilidade mínima, para cada equipamento utilizado no processo alvo de estudo neste trabalho, estabelecido como meta, é de $97 \%$.

\section{3 Índice de Disponibilidade Física}

Para calcular a disponibilidade da máquina injetora 1800-01, utilizada no processo de fabricação das carcaças F-15, foram utilizadas informações fornecidas pela Empresa Alfa. Na TAB. 1, estão contidos dados de setembro de 2016 a abril de 2017 referentes ao número de horas paradas e tempo total previsto para funcionamento da máquina injetora BUHLER 1800-01. 
Tabela 1 - Tempo de paradas e horas previstas de produção da máquina 1800-01

\begin{tabular}{ccc}
\hline Mês & Tempo Total de Paradas (h) & Horas Previstas de Produção (h) \\
\hline Set/16 & 26,22 & 504,00 \\
Out/16 & 26,58 & 504,00 \\
Nov/16 & 20,25 & 504,00 \\
Dez/16 & 31,5 & 504,00 \\
Jan/17 & 19,25 & 504,00 \\
Fev/17 & 39,66 & 504,00 \\
Mar/17 & 24,84 & 504,00 \\
Abr/17 & 30,58 & 504,00 \\
\hline
\end{tabular}

Fonte: Dos autores (2017).

Uma vez calculado o índice mensal de disponibilidade física do equipamento, permitiu-se visualizar a distância entre o realizado e o planejado pela empresa. Por meio da GRAF. 1, é possível identificar que, em apenas um dos oito meses analisados, a disponibilidade da máquina em estudo esteve acima dos parâmetros estabelecidos. Para cálculo da disponibilidade, utilizou-se a Equação (1), apresentada no Referencial Teórico.

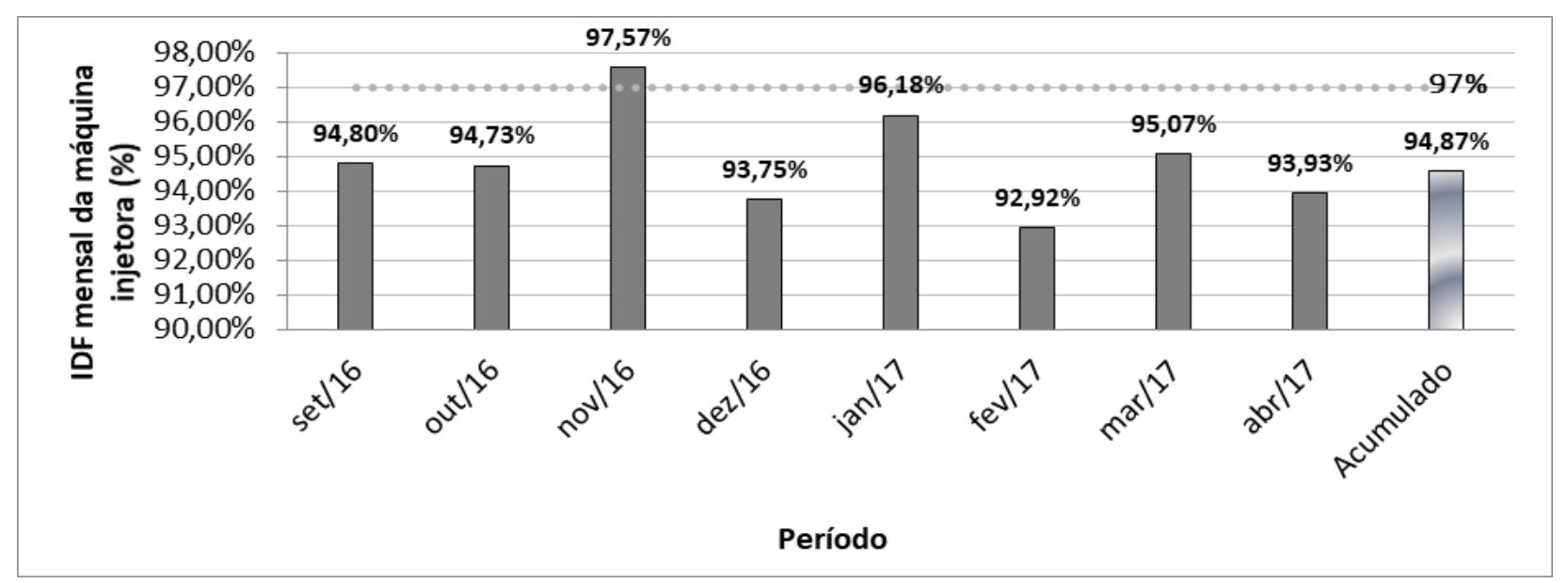

Gráfico 1 - IDF mensal da máquina injetora 1800-01 x Meta de disponibilidade Fonte: Dos autores (2017).

Em sequência, identificaram-se os dez tipos de falhas mais significativas no processo. Os critérios adotados para tal mensuração consideraram todos os motivos recorrentes e com impacto superior a 1h/mês (lê-se uma hora por mês); as demais, foram tratadas como "outros", conforme sugerido por Campos (2004). Isto se pautou em obediência ao princípio de Pareto, segundo o qual, poucos são os fatores responsáveis pela maior parte dos resultados. Os dados foram então agrupados e quantificados por meio da GRAF. 2, de modo a mostrar a representatividade de cada um dos tipos de paradas em relação ao tempo total indisponível. 


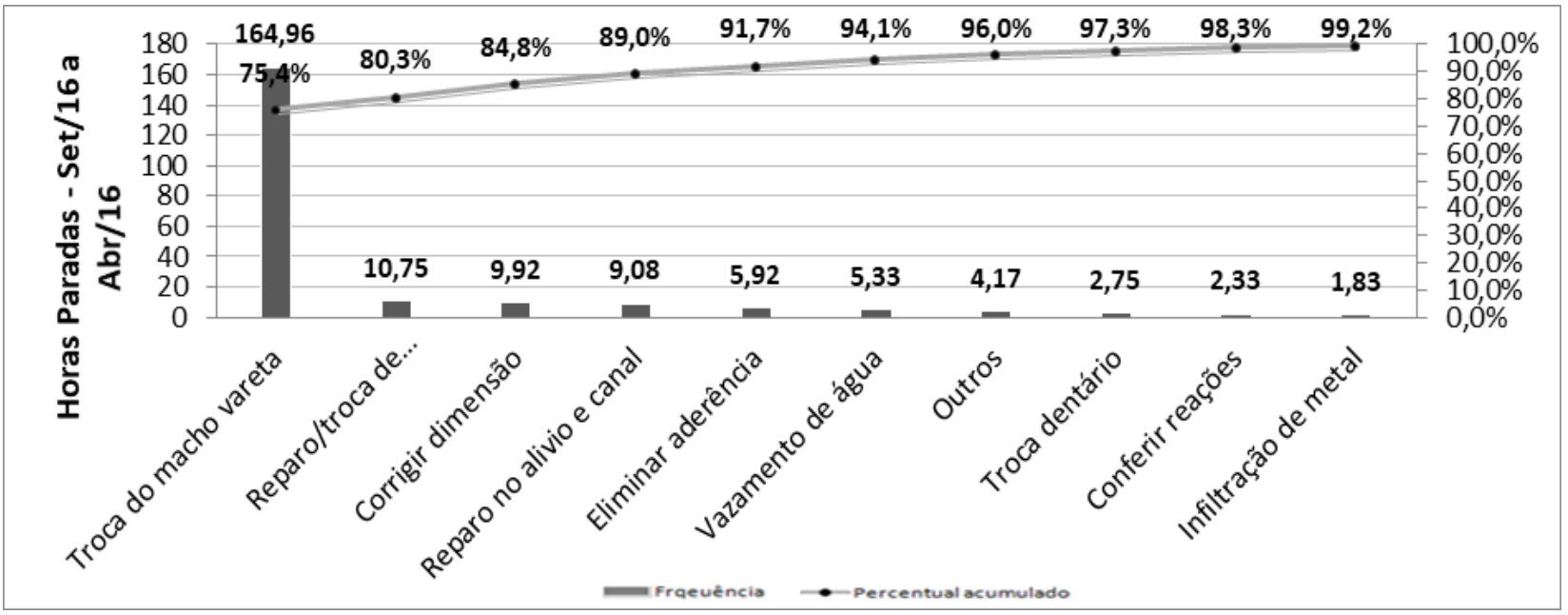

Gráfico 2 - Gráfico de Pareto: Motivos de parada da Máquina 1800-01 Fonte: Dos autores (2017).

Ao analisar o gráfico de Pareto, torna-se evidente a representatividade das falhas ocasionadas pela troca do macho vareta. A mesma, correspondendo à 164,96 horas, representa $75 \%$ do total e comprova a afirmação de Werkema (1995), no qual a solução de aproximadamente $20 \%$ das causas representa uma diminuição de cerca de $80 \%$ no número de perdas totais. Elaborou-se também a GRAF. 3, onde se evidencia que, uma vez sanados os problemas que ocasionam a parada da máquina, decorrente da necessidade de se realizar a troca do macho vareta, o índice almejado pela organização, de $97 \%$ de disponibilidade, seria devidamente alcançado.

Através da interpretação do referido gráfico verifica-se um índice de 4,09\% de horas paradas para realização da troca do macho vareta, em relação ao tempo total estimado de horas previstas de produção. Estimando-se que, se houvesse um índice zero de paradas para qualquer intervenção por este motivo, o IDF do processo subiria para 98,66\%. É interessante ressaltar que nenhuma das demais causas, se tratadas individualmente, a ponto de se obter zero paradas, seria suficiente para superação da meta estabelecida, o que reforça ainda mais a significância do modo de falha associada à troca do macho vareta. Tendo como base o objetivo proposto pelo trabalho em questão, e considerando a representatividade do macho vareta, este foi o principal modo de falha mapeado no processo. Juntos, os demais motivos totalizam $25 \%$, sendo que, o segundo mais significativo, teve um impacto quinze vezes menor. Logo, pode-se afirmar que a troca do macho vareta é a principal causa que afeta o IDF do equipamento envolvido.

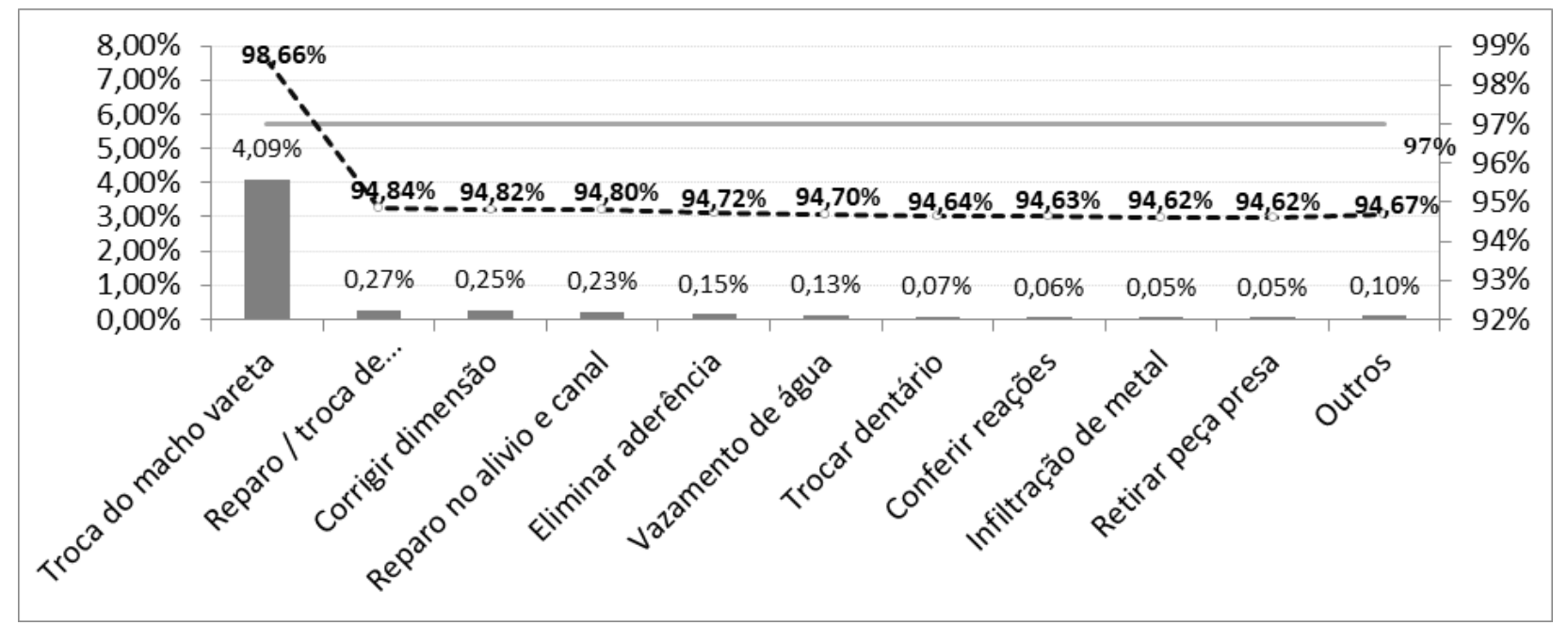

Gráfico 3 - IDF a ser alcançado eliminando-se os motivos de paradas Fonte: Dos autores (2017). 


\subsection{Descrição da Falha}

O molde utilizado no processo produtivo das carcaças F-15 é composto de cinco machos móveis, sendo, um deles, o "macho vareta" ou "pino macho", conforme mostra a FIG. 2.
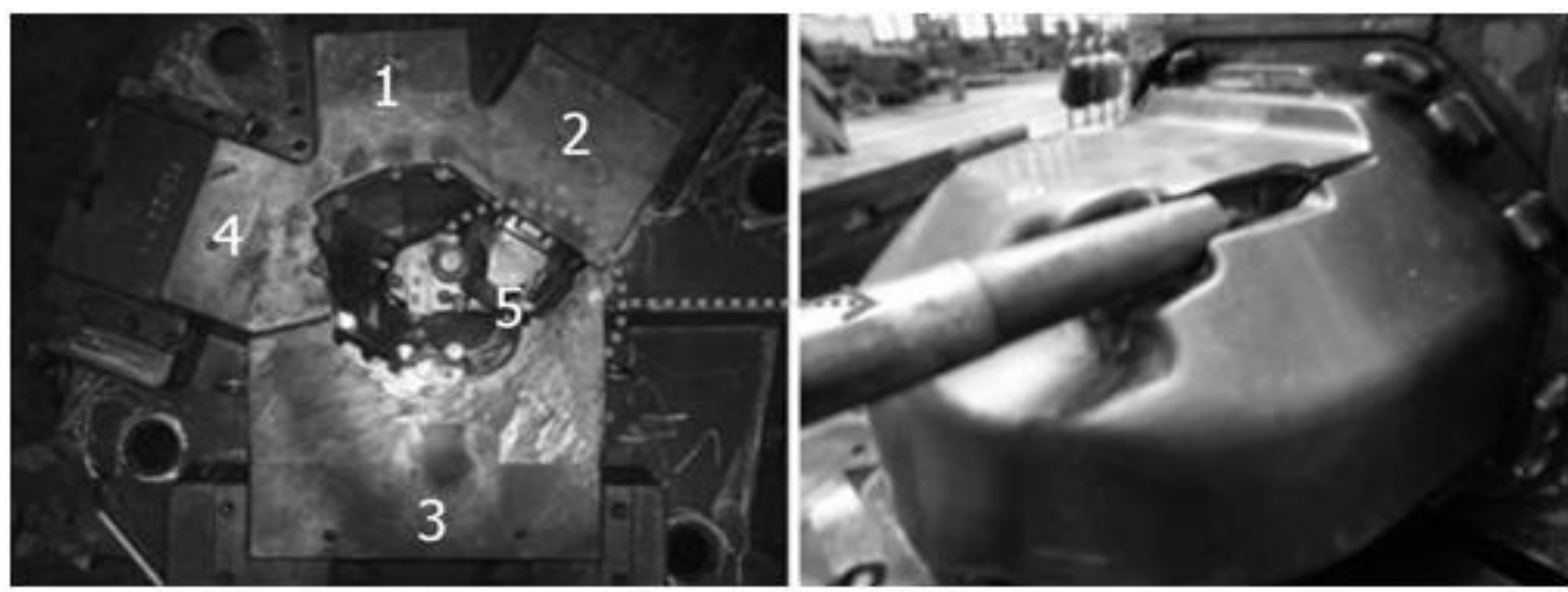

Figura 2 - Macho Vareta

Fonte: Dos autores (2017)

O princípio de funcionamento do macho vareta consiste em avançar ou recuar, a depender do estágio em que se encontra o processo de injeção sob pressão, para formação de uma das partes da peça a ser fundida. Sua função é confeccionar um pré-furo no produto final. Basicamente o macho vareta permanece na condição de avançado e, tão logo terminado o processo de solidificação, ele se recua, de modo a permitir que a peça seja extraída, sem deixar resquícios que possam provocar retenção da peça fundida.

Como este, existem outros conjuntos móveis no ferramental, que se movimentam em sincronia e que definem o restante da peça. Sendo assim, qualquer situação que venha interferir no correto funcionamento deste sistema, pode acarretar na danificação de algum componente, ocasionando uma parada no equipamento e, consequentemente, a interrupção do processo produtivo. De acordo com o histórico de informações disponibilizado pela Empresa Alfa, três são os principais motivos de falha envolvendo a necessidade de parada do equipamento para substituição do macho vareta: quebra, desgaste e empeno do pino. Segundo ainda dados verificados junto à Empresa Alfa, entre os três fatores apresentados, o empeno é o que apresenta maior índice de ocorrência. Um exemplo de macho vareta empenado pode ser verificado na FIG. 3 (a).

Seguido pelo empeno, outra situação bastante significativa, é a ocorrência do desgaste do macho vareta. $\mathrm{O}$ alto índice de atrito entre o referido componente e as demais partes que compõem o sistema, provoca o seu desgaste que, após um determinado nível, inviabiliza sua utilização. A FIG. 3 (b) apresenta um macho vareta com significativo índice de desgaste. 

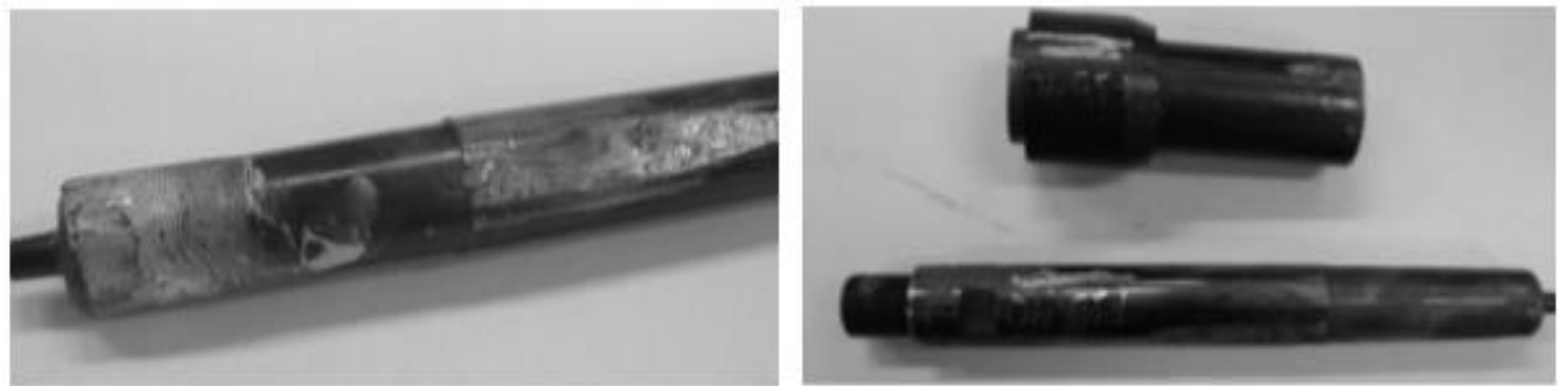

Figura 3 - Macho vareta empenado (a) e Macho vareta desgastado (b) Fonte: Dos autores (2017)

\subsection{Definição do Fluxo do Processo e Variáveis Críticas}

O mapeamento das causas relacionadas à troca do macho vareta se deu, no primeiro momento, na observação do processo de montagem do molde utilizado na produção das carcaças. No ato da observação, entrevistas não estruturadas foram realizadas com o Gestor de Processos, responsável pela área de fundição que utiliza, como método, a injeção sob pressão, bem como com demais colaboradores envolvidos. Observou-se, em seguida, o processo de fabricação das peças. Simultaneamente, nova entrevista não estruturada foi realizada, desta vez, com um dos operadores da máquina. Na ocasião, quatro colaboradores se revezavam em três turnos de trabalho. Os questionamentos e extração de percepções mencionadas tiveram como intuito ampliar o conhecimento e entendimento do processo, visando, em momentos posteriores, possuir a competência necessária para mensurar os fatores que afetam o IDF do equipamento.

As informações coletadas foram então descritas e estratificadas em etapas. Realizou-se também um brainstormig com a equipe de engenharia de processos, de modo a identificar as variáveis críticas relacionadas a cada uma das etapas mensuradas. Dentre os dezenove estágios do processo, quatro foram classificados como possuindo fatores críticos correlacionados, sendo eles: o momento de ligação das mangueiras, a habilitação do software e sensores, momento de abertura do macho vareta e o fechamento automático da máquina. Identificou-se quatro variáveis críticas, onde falhas associadas estariam acarretando o empeno, desgaste e/ou quebra do pino. Além das falhas identificadas, constatou-se também que não havia um checklist para monitoração destas, o que seria necessário uma vez que foram consideradas como sendo de alta criticidade.

Conduzida de forma participativa e com a presença de colaboradores do setor de engenharia de processos e do gestor da equipe de manutenção, novo brainstorming foi realizado para estratificar tais falhas. A reunião teve como direcionamento os seguintes questionamentos: Em todas as variáveis críticas identificadas existem falhas? Como estas ocorrem? Como resultado, cinco situações foram devidamente identificadas, sendo elas: (i) Falha no posicionamento do sensor de atuação dos machos; (ii) Falha elétrica no sinal de comando dos sensores; (iii) Falha de segurança hidráulica; (iv) Sequência inadequada de fechamento dos machos e (v) Falta de monitoração das variáveis do processo.

Posteriormente utilizou-se como ferramenta de análise, o Diagrama de Causa e Efeito, conforme apresentado na FIG. 4. Tal situação permitiu que fossem identificadas as causas raízes das falhas relacionadas como responsáveis por afetar a disponibilidade do equipamento estudado. Identificou-se que não existe um padrão de montagem dos sensores. 
Os mesmos são responsáveis por comandar, eletronicamente, o avanço e retorno dos machos, dando sinais ao equipamento para prosseguir com os próximos passos do processo; neste caso, para a abertura e fechamento das injetoras e consequentemente para injeção e extração das peças. Uma vez que estes não se encontrem devidamente posicionados, haverá variações nas posições de avanço dos machos, principalmente do macho vareta que, por se tratar de um processo padronizado, quando não respeitado, pode acarretar em danos para a produção. A velocidade de avanço e recuo do macho vareta, quando realizada de forma incompatível, poderá ocasionar em sua quebra, desgaste ou empeno, principalmente em virtude de pequenas colisões ocorridas durante o ciclo.

Evidenciou-se juntamente com os responsáveis pela manutenção corretiva, considerável índice de troca dos machos vareta em decorrência de falhas no sinal de comando dos sensores. Em algumas situações, pôde-se constatar que durante o processo de fabricação, os machos vareta avançavam ou recuavam em momentos indevidos decorrente de um sinal elétrico enviado de forma inadequada, o que ocasionava dano ao referido componente.

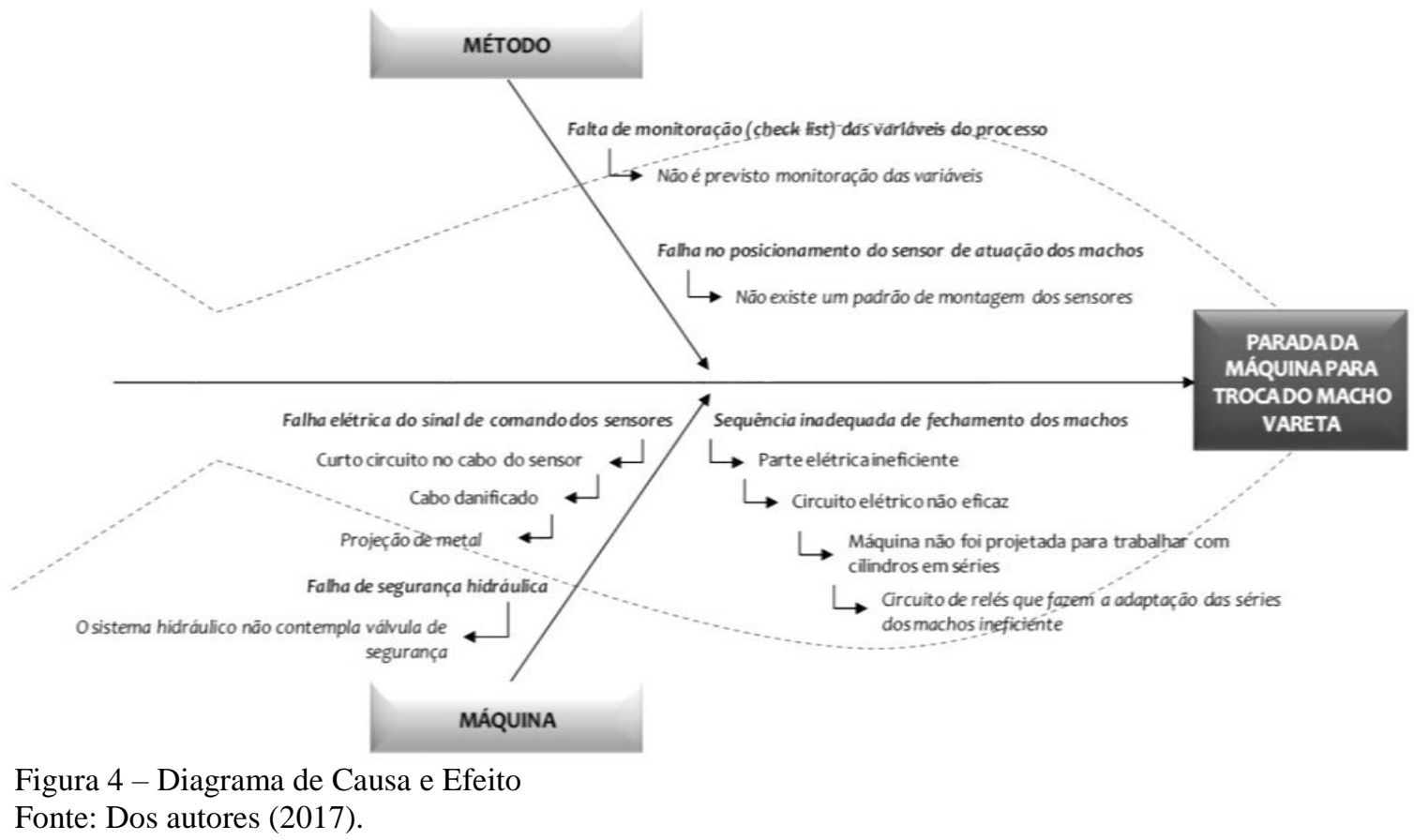

Observou-se que sempre que tais situações ocorriam, as ações adotadas restringiam-se a investigações na parte elétrica, não se realizando um maior aprofundamento do porquê da ocorrência. Como normalmente estas situações relacionavam-se a pequenos rompimentos nas fiações, estas eram devidamente substituídas e dava-se a situação por encerrada.

A partir destas informações, procedeu-se com uma investigação acerca do por que destas falhas elétricas e constatou-se que as mesmas eram provenientes da projeção de metal líquido, no caso o alumínio, pela máquina injetora. $\mathrm{O}$ contato deste material incandescente com a fiação do referido equipamento, ocasionava as falhas elétricas que enviavam o sinal de avanço de forma inconsistente. Para que os machos móveis do molde utilizados no processo de fabricação das carcaças F-15 sejam devidamente mantidos em suas posições adequadas, tanto no processo de injeção quanto no processo de formação das peças, utiliza-se um sistema hidráulico para realizar as movimentações dos cilindros utilizados pelo equipamento. 
O princípio do bom funcionamento deste sistema encontra-se diretamente relacionado à manutenção das pressões estabelecidas para sustentação dos moldes. Havendo perda de pressão, acarretará em uma variação no posicionamento, principalmente do macho inferior do molde, que tem um peso de aproximadamente $1.275 \mathrm{~kg}$, tendendo este a se movimentar para baixo, visto a posição em que se encontra montado na máquina. Em virtude do sistema do macho vareta estar fixado sobre o macho inferior, este movimento indevido influenciará em uma colisão entre eles, ocasionando dano, quebra, empeno e/ou desgaste do pino. Verificou-se que não existe no equipamento, nenhuma válvula de segurança que impeça o avanço e, principalmente, o recuo do macho vareta devido à perda de pressão.

No momento do fechamento automático da máquina, o ciclo de fechamento e recuo dos machos possuía diferenças sequenciais em decorrência de parâmetros do próprio equipamento. Quando se analisou a máquina em seu processo de funcionamento, verificaram-se cinco injetoras trabalhando de forma simultânea. A máquina não fora projetada para trabalhar com moldes e cinco peças móveis em séries, e o circuito de relés que realiza a adaptação das mesmas não era eficiente. Verificou-se que esta situação estava ocasionando o fechamento dos machos de maneira inadequada, causando assim, avarias nestes componentes. Observou-se que todas as variáveis críticas identificadas na definição do fluxo do processo não possuíam procedimento de monitoração a ser executado pela equipe de manutenção e processos. A não observância destes fatores preventivamente propiciava as demais falhas aqui identificadas. Todas as variáveis que podem ser alteradas em consequência do processo produtivo devem ser monitoradas periodicamente, garantindo assim a funcionalidade do sistema e evitando falhas que possam comprometer o ciclo produtivo ou gerar danos ao molde e/ou equipamento.

A partir da estratificação das situações identificadas, pode-se constatar que as causas raízes das falhas que geravam a indisponibilidade no processo de fabricação eram: falta de padrão para montagem dos sensores; projeção de metal incandescente sobre o cabeamento dos sensores; ausência de válvula de segurança em caso de perda de pressão do sistema hidráulico; ineficiência do circuito de relés que fazem a adaptação das séries dos machos; não monitoração das variáveis do processo.

\section{CONCLUSÕES}

Com base nos resultados obtidos no presente trabalho, concluiu-se que, as principais causas que afetam a disponibilidade do equipamento estudado foram devidamente identificadas e mapeadas, podendo assim ser utilizadas como fator de referência para implementação de ações de melhoria do processo. Para alcance dos objetivos estabelecidos, foram realizadas pesquisas bibliográficas que serviram como base para os posicionamentos aqui defendidos, assim como para o desenvolvimento das análises. Contatou-se um índice de 4,09\% de horas paradas para realização da troca do macho vareta. Estimando-se que, se houvesse um índice zero de paradas para qualquer intervenção por este motivo, a disponibilidade do processo subiria para 98,66\%. É interessante ressaltar que nenhuma das demais causas, se tratadas individualmente, a ponto de se 
obter zero paradas, seria suficiente para superação da meta estabelecida, o que reforça ainda mais a significância do modo de falha associada à troca do macho vareta.

O estudo comprovou que a solução da menor parte dos fatores, proporciona a solução da grande maioria dos problemas, onde as falhas que ocasionavam a troca do macho vareta foram as de maior relevância. A partir da identificação e estratificação do principal fator responsável pela parada do equipamento, pode-se identificar as principais causas que ocasionavam estas paradas. Concluiu-se que, cinco são causas as responsáveis por afetar a disponibilidade do equipamento estudado, sendo elas: falha no posicionamento do sensor de atuação dos machos; falha elétrica do sinal de comando dos sensores; falha de segurança hidráulica; sequência de fechamento dos machos inadequadas e falta de monitoração das variáveis do processo. Além disto, com o desenvolvimento deste trabalho evidenciou-se a importância da disponibilidade física dos equipamentos no que se refere à maior produtividade e qualidade dos processos, em especial na indústria automobilística, que se caracteriza pela crescente expansão e alta competitividade.

Por fim, mas não menos importante, sugere-se como trabalhos futuros a mensuração da eficiência do sistema, bem como um estudo sobre os tempos de setup envolvidos no processo. Para tal, recomenda-se a medição dos tempos e movimentos associados à execução da atividade e posterior remodelação do processo, se necessária.

\title{
A STUDY ABOUT THE CAUSES THAT GENERATE THE UNAVAILABILITY IN THE PROCESS OF MANUFACTURE OF AUTOMOTIVE PARTS
}

\begin{abstract}
This work aimed to map the main causes that affect an injection machine Availability Index, which is part of an automotive components manufacturing process. A comparative study was carried out between the Availability Index established and conducted between September 2016 and April 2017. It was found that the average attendance rate of $94.98 \%$ was lower than the target of $97 \%$. Subsequently, the main factors responsible for this situation were identified, where it was possible to verify, by means of the application of a Pareto Chart, that $75 \%$ of the stops occurred were associated with the exchange of the component known as "Macho Vareta". After identifying the most significant failure (s), a brainstorming was carried out with the employees of the engineering sector involved in the production process. Then, through a Ishikawa diagram, a stratification a stratification process of this factor identified as main was carried out, thus obtaining the main causes that caused the equipment stops. The applied methodology consists on: number of hours in which the machines are stopped analysis, provided by the company Alpha, conducting four visits in loco with the unstructured interviews development with those involved in the process and application of the situations involved quality tools. According to the presented analyzes it is possible to mapping the main causes that affect the studied equipment availability, being: failure in the "Machos" sensor action positioning; electrical fault in the sensors control signal; hydraulic safety failure; improper closure sequence of males; monitoring lack of process variables. As a result, the Availability Index estimate was equal to $98.66 \%$
\end{abstract}

Keywords: Fault mapping. Availability. Maintenance.

\section{REFERÊNCIAS}

ASSOCIAÇÃO BRASILEIRA DE NORMAS TÉCNICAS - ABNT. NBR 5462: Confiabilidade e Mantenabilidade. Rio de Janeiro, 1994. 37 p.

ASSOCIAÇÃO NACIONAL DOS FABRICANTES DE VEÍCULOS AUTOMOTORES ANFAVEA. Desempenho da indústria automobilística: maio de 2017. São Paulo, 2017.

ForSci.: r. cient. IFMG campus Formiga, Formiga, v. 6, n. 3, e00272, jul./dez. 2018. 
Disponível em: <http://automotivebusiness.com.br/abinteligencia/pdf/desempenho-janmaio.pdf>. Acesso em: 28 maio 2017.

BAENINGER, Rosana. A nova configuração urbana no Brasil: desaceleração metropolitana e redistribuição da população. In: ENCONTRO NACIONAL DE ESTUDOS POPULACIONAIS, 11., 1996, Belo Horizonte. Anais... Belo Horizonte: ABEP, 1996, p. 729-772. Disponível em: <http://www.abep.org.br/publicacoes/index.php/anais/article/view/863/829>. Acesso em: 28 maio 2017.

BÜHLER GROUP. Fundição sob pressão tradicional de alumínio. Joinville, [2016]. Disponível em <http://www.buhlergroup.com/southamerica/pt/tecnologias-de-processo/fundiosobpresso/fundio-sob-presso-tradicional-de-alumínio.htm>. Acesso em: 23 mai. 2016.

CAMPOS, Vicente Falconi. TQC: controle da qualidade total (no estilo japonês). 8. ed. Nova Lima: INDG, 2004. 256 p.

CASSIOLATO, Jose Eduardo; SZAPIRO, Marina Honorio de Souza. Os dilemas da política industrial e de inovação: os problemas da Região Sudeste são os do Brasil. In: LEAL, Claudio Figueiredo Coelho et al. (Org.). Um olhar territorial para o desenvolvimento: Sudeste. Rio de Janeiro: BNDES, 2015.

DHILLON, Balbir S. Maintainability, maintenance, and reliability for engineers. Boca Raton: CRC/Taylor \& Francis, 2006.

GORGULHO, Guilherme et al. Gestão eficiente de projetos Lean Six Sigma: um estudo de caso em uma indústria automotiva. Revista de Ciência \& Tecnologia, v. 20, n. 39, p. 3-16, 2014. Disponível em: <https://www.metodista.br/revistas/revistasunimep/index.php/cienciatecnologia/article/view/3184/1904>. Acesso em: 28 maio 2017.

LAFRAIA, José R. Barusso. Manual de confiabilidade, mantenabilidade e disponibilidade. Rio de Janeiro: Qualitymark, 2001. 374 p.

MARCORIN, Wilson Roberto; LIMA, Carlos R. Camello. Análise dos custos de manutenção e de não manutenção de equipamentos produtivos. Revista de Ciência \& Tecnologia, v. 11, n. 22, p. 35-42, jul./dez. 2003.

MARTINS, Petrônio Garcia; LAUGENI, Fernando Piero. Administração da produção. São Paulo: Saraiva, 2012. 272 p.

MENDES, Angélica Alebrant; RIBEIRO, José Luis Duarte. Estabelecimento de um plano de manutenção baseado em análises quantitativas no contexto da MCC em um cenário de produção JIT. Production. Porto Alegre, v. 24, n. 3, p. 675-686, jul./set. 2014. Disponível em: <http://www.scielo.br/pdf/prod/v24n3/aop_t6_0002_0669.pdf >. Acesso em: 28 maio 2017.

MISRA, Krishna B. Maintenance engineering and maintainability: an introduction. In: MISRA, Krishna B. (Ed.). Handbook of performability engineering. London: Springer, 2008. p. 755772.

MUNARIN, Lívio Augusto et al. O Controle interno nas empresas no setor de autopeças como instrumento de apoio na gestão dos estoques. In: SEMINÁRIO INTERNACIONAL DE INTEGRAÇÃO E DESENVOLVIMENTO REGIONAL, 1., 2013, Ponta Porã. Anais... Ponta Porã, 2013. Disponível em: <https://anaisonline.uems.br/index.php/ecaeco/article/download /2753/2826>. Acesso em: 28 maio 2017.

PINTO, Alan. K.; XAVIER, Julio. A. Nascif. Manutenção: função estratégica. 2. ed. Rio de Janeiro: Qualitymark, 2001.

SMITH, David J. Reliability, maintainability and risk: practical methods for engineers. Oxford, UK: Butterworth-Heinemann, 2017. 
WERKEMA, Maria. C. Catarino. Ferramentas estatísticas básicas para o gerenciamento de processos. v. 2. Belo Horizonte: Fundação Cristiano Ottoni, Escola de Engenharia da UFMG, 1995. $384 \mathrm{p}$

XENOS, Harilaus G. D'Philippos. Gerenciando a manutenção produtiva: o caminho para eliminar falhas nos equipamentos e aumentar a produtividade. Nova Lima: INDG, 2004. 302 p.

\section{DADOS DO AUTOR}

\section{Andressa Amaral de Azevedo}

E-mail: andressa@pucminas.br.

Currículo lattes: http://lattes.cnpq.br/4655939441959542.

Doutoranda em Administração pela PUC Minas. Mestre em Engenharia de Produção, área de concentração Produção e Logística, pela Universidade Federal de Minas Gerais (UFMG). Especialista em Docência no Ensino Superior e Gestão Acadêmica pelo Instituto Metodista Izabela Hendrix (IMIH). Graduada em Engenharia de Produção pela Universidade Federal de Viçosa (UFV). Docente do Departamento de Engenharia de Produção da Pontifícia Universidade Católica de Minas Gerais (PUC Minas).

\section{Tiago Silveira Gontijo}

E-mail: tiago.gontijo@izabelahendrix.edu.br.

Currículo lattes: http://lattes.cnpq.br/2865658247618316.

Graduando em Engenharia de Produção (Universidade FUMEC). Bacharel em Ciências Econômicas (UFV), Mestre em Engenharia de Produção (UFMG). Doutorando em Saúde Pública pela Faculdade de Medicina da UFMG. Docente no Centro Universitário Metodista Izabela Hendrix.

\section{Erick Victor}

E-mail: erickfvictor1@yahoo.com.br.

Graduado em Engenharia de Produção pela Faculdade Pitágoras de Belo Horizonte.

\section{Leonardo Souza}

E-mail: leolopes19861@yahoo.com.br.

Graduado em Engenharia de Produção pela Faculdade Pitágoras de Belo Horizonte.

\section{Taís Oliveira}

E-mail: tais.oliveira31@gmail.com.

Graduado em Engenharia de Produção pela Faculdade Pitágoras de Belo Horizonte. 